\title{
Proposals for an Assessment Method of Accessibility and Usability in Web Software
}

\author{
Edson Corrêa Teracine $^{1}$ and Fabíola Calixto Matsumoto ${ }^{2}$ \\ ${ }^{1}$ Centro de Tecnologia da Informação Renato Archer, \\ Divisão de Segurança de Sistemas de Informação, Campinas, São Paulo, Brazil \\ ${ }^{2}$ Centro de Tecnologia da Informação Renato Archer, \\ Centro Nacional de Referência em Tecnologia Assistiva, Campinas, São Paulo, Brazil \\ \{edson.teracine, fabiola.calixto\}@cti.gov.br
}

\begin{abstract}
Nowadays, applications hosted in the Internet face the challenge to serve a wider range of end users with a potential variety of disabilities that has to be taken into account in the process of Web designing and programming. In this context, the research and development of assessment methods to validate software accessibility have grown in importance. The present document shows a comparative study of methods applied for assessment of the characteristics accessibility and usability in a complementary way, in order to collaborate with the improvement of assessment methods in the implementation of accessibility in Websites and Web applications.
\end{abstract}

Keywords: Assessment Methods of Accessibility and Usability of Software, Assessment of the Characteristics Accessibility and Usability in Web Software.

\section{Introduction}

This study has started from the observations made during assessments and production of accessible Websites, considering the currently available methods for validating and verifying the characteristic accessibility in Web applications.

Aiming at overcoming the limitations identified, new perspectives are proposed by the integration of complementary methods of assessment of accessibility and usability found in the literature.

The reminder of this paper is as follows: Section 2 presents standards and assessment methods elected for the study; Section 3 contains methodology and precepts adopted to conduct the comparative analysis of methods; Section 4 shows propositions and specifications made for the integration of methods and the proposals for an assessment method of accessibility and usability in Web software; Section 5 concludes the paper.

\section{Assessment Methods of Web Accessibility and Usability}

In the context of the considered methods of assessment and validation of accessibility, the need to identify standards which represent a general source of reference for most of the currently available methods was defined. This leads to considering the Web 
Content Accessibility Guidelines - WCAG 2.0 [1] as the actual reference standards for accessibility policies in the Web and for this study. At the same time, the presentation of a conceptual approach level, which represents a fundamental premise for integrating the methods under comparison, is adopted as an important selection criterion.

The adoption of a complementary vision to the characteristic accessibility considering usability attributes for an effective complementation justifies the attention upon software product quality [2] and the inclusion of MEDE-WEB - Quality Assessment Method of Websites version 2005 [3] in the study, opening both the possibility of new aspects to be assessed and the important points of contact between the characteristics (accessibility and usability).

The following standards and assessment methods of accessibility and usability in the Web are considered to perform the comparative study:

- Web Content Accessibility Guidelines WCAG 2.0 [1];

- Method of Model of Accessibility in Electronic Government - Model e-Mag [4];

- Method of WebAIM's WCAG 2.0 Checklist for HTML Documents - CHD [5];

- MEDE-WEB - Quality Assessment Method of Websites version 2005 [3].

\subsection{Web Content Accessibility Guidelines - WCAG 2.0}

According to W3C [1], Web Content Accessibility Guidelines WCAG 2.0 consists of a set of accessibility guidelines created by WAI (Web Accessibility Initiative) with the goal of making Web content more accessible to a broad group of people with disabilities, in addition to Web users in general.

WCAG is structured in layers of guidance, including principles, guidelines, success criteria, sufficient and advisory techniques, and represents the conceptual reference model for the treatment of accessibility in the Web worldwide, used for many of the currently existing assessment methods.

For the purpose of the comparative study, only WCAG's layers of guidance until success criteria, which are testable statements for the implementation of related guidelines, will be considered in order to not deal specifically with practical examples of Web development technologies (programming languages or codes). Therefore, the layer of techniques will not be a subject of this study, to establish a basis for comparison only on a conceptual level.

\subsection{Method of Model of Accessibility in Electronic Government - Model e-Mag}

The Electronic Government (e-GOV) [4], as an initiative of the brazilian Government, created the Model of Accessibility in Electronic Government e-Mag version 3.0 (Model e-Mag) as a result of the study of accessibility rules and comparison of standards adopted by different countries.

According to e-GOV, Model e-Mag assumes three steps to perform the process of developing an accessible site:

1) the application of Web standards; 2) the application of accessibility guidelines; 3 ) the performance of accessibility assessment. In the present study, the checklists offered by Model e-Mag for the assessment of accessibility in the Web are considered. 
Model e-Mag has as its reference the WCAG's hierarchical structure, layers of guidance and concepts, being in a direct relation to them.

For the comparative study, checkpoints of e-Mag's method will be considered just in their "Item" topics just to keep the focus on a conceptual level, excluding any particular technological solution approach for Web programming and development ("What to evaluate" topics).

\subsection{Method of WebAIM's WCAG 2.0 - CHD}

The Web Accessibility In Mind (WebAIM) [5] is a collaborative community that aims to help make Web more accessible to individuals with disabilities.

The recommendations proposed by the method CHD are based on WCAG's specifications, following the same structure with its respective layers of guidance, but with a particular interpretation of WCAG's guidelines and success criteria, with suggestions for fulfilling these criteria.

\subsection{Quality Assessment Method of Websites version 2005 - MEDE-WEB}

MEDE-WEB is a method created in the Centro de Tecnologia da Informação Renato Archer (CTI) [3], specifically by the team of researchers from Division of Process and Software Quality Improvement.

According to CTI, MEDE-WEB can be used in conducting the process of assessment and verification of the characteristic usability in Websites, through the application of assessment items that express specific quality requirements, verifiable in a Web software product in use. The degree of fulfillment of requirements, which characterize certain quality attributes, is what determines the quality level of the assessed product. To do so, components or integrating elements of a Website and aspects applicable to each component are considered in a hierarchical structure, as in the example shown in Figure 1:

\section{Titles (body of Web pages) $\quad \leftarrow$ Web site component \\ Content $\leftarrow$ component's aspect}

\subsection{Clarity $\leftarrow$ aspect's attribute}

Titles:

.1. are clear

A=All; $A A=$ AlmostAll; $\mathbf{S}=$ Some; $\mathbf{N}=$ None. assessment

2. are significant: items

$\mathrm{A}=\mathrm{All} ; \mathrm{AA}=$ Almost All; $\mathbf{S}=$ Some; $\mathbf{N}=$ None.

3. avoid technical terms that dificult understanding; (usability $\mathrm{A}=\mathrm{All} ; \mathrm{AA}=$ Almost All; $\mathbf{S}=$ Some; $\mathbf{N}=$ None. requirements)

Fig. 1. Example of MEDE-WEB Assessment Items and Usability Requirements 
However, as already mentioned, there are common points between the characteristics accessibility and usability of software, presented by MEDE-WEB on many of its assessment items.

\section{$3 \quad$ Methodology of Comparative Analysis of Assessment Methods of Accessibility and Usability in Web Software}

The methodology of comparative analysis aims to identify the layers of guidance presented in the studied methods, as well as their application and correlations in the hierarchical degrees of the structure of layers. And, at the same time, to consider the necessary adjustments for the construction of a new proposal of guidance, from the raised observations.

The layers of guidance based on WCAG 2.0, as well as their correspondence with each other considering the methods, are shown in Table 1:

Table 1. Layers of Guidance of the Methods

\begin{tabular}{|c|c|c|c|}
\hline \multicolumn{4}{|c|}{ Layers of Guidance of the Methods } \\
\hline $\mathbf{A}$ & B & $\mathbf{C}$ & D \\
\hline $\begin{array}{l}\text { - WCAG Layer } \\
\text { of Principles } \\
\text { - CHD Layer } \\
\text { of Pinciples }\end{array}$ & $\begin{array}{c}\text { - WCAG Layer } \\
\text { of Guidelines } \\
\text { - CHD Layer of } \\
\text { Guidelines }\end{array}$ & $\begin{array}{l}\text { - WCAG Layer of } \\
\text { Success criteria } \\
- \text { e-Mag Layer of } \\
\text { Recommendations } \\
- \text { CHD Layer of } \\
\text { Success criteria }\end{array}$ & $\begin{array}{l}\text { - e-Mag Layer of } \\
\text { Checkpoints } \\
\text { (Items) } \\
\text { - CHD Layer of } \\
\text { WebAIM } \\
\text { Recommendations }\end{array}$ \\
\hline
\end{tabular}

\section{$4 \quad$ Proposals for an Assessment Method of Accessibility and Usability in Web Software}

Proposals will be presented for a new model of approach and assessment method of the characteristics accessibility and usability in Web environment by integrating the methods studied and the adoption of new points of view in the treatment of accessibility and usability requirements.

\subsection{New Hierarchical Structure of Layers of Guidance}

The need of integration of the assessment methods, in the purpose of creation of proposals for a new model, assumes the revision and adaptation of the layers of guidance already identified in a new structure of layers. The presented reinterpretation of the layers in which accessibility is handled by the methods studied has the aim of 
creating a common field to enable such integration. The redefinition of layers in a new configuration is shown schematically in Figure 2:

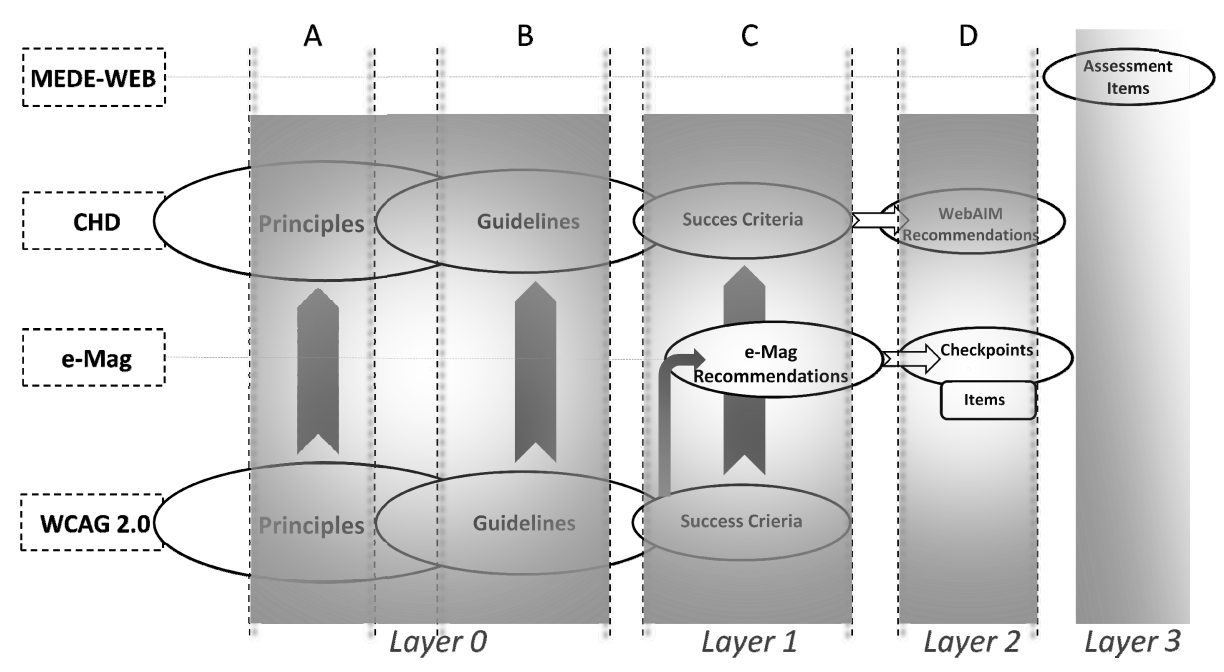

Fig. 2. Layers of Guidance of the Methods and Integration in a New Structure (Layers 0 to 3)

Specifications are shown in Table 2 for the new proposed structure of layers of guidance, based on the methods studied:

Table 2. Layers of Guidance - Integration of the Methods

\begin{tabular}{|c|c|c|c|c|}
\hline \multicolumn{5}{|c|}{ Layers of Guidance - Integration of the Methods } \\
\hline $\begin{array}{l}\text { Layer of Guidance } \\
\text { Number and Name }\end{array}$ & $\begin{array}{c}\text { Layer } 0 \\
\text { Layer of } \\
\text { Principles } \\
\end{array}$ & $\begin{array}{c}\text { Layer } 1 \\
\text { Layer of } \\
\text { Guidelines } \\
\end{array}$ & $\begin{array}{l}\text { Layer } 2 \\
\text { Layer of } \\
\text { Checking } \\
\end{array}$ & $\begin{array}{c}\text { Layer } 3 \\
\text { Layer of } \\
\text { Requirements }\end{array}$ \\
\hline Definition & $\begin{array}{lr}\text { Patterns, } & \text { principles } \\
\text { and } & \text { general } \\
\text { precepts } & \text { that } \\
\text { characterize } & \text { an } \\
\text { accessible } & \\
\text { information } & \end{array}$ & $\begin{array}{l}\text { Guidelines testable } \\
\text { and applicable to } \\
\text { Web environment } \\
\text { that make their } \\
\text { content accessible }\end{array}$ & $\begin{array}{l}\text { Specifications of } \\
\text { accessibility } \\
\text { requirements that } \\
\text { allow to implement } \\
\text { and validate } \\
\text { Guidelines } \\
{[\text { Layer 1] }}\end{array}$ & $\begin{array}{l}\text { Specifications in a } \\
\text { more detailed } \\
\text { degree that } \\
\text { differentiate and } \\
\text { extend, through } \\
\text { usability } \\
\text { requirements, the } \\
\text { accessibility } \\
\text { requirements of } \\
\text { Checking } \\
\text { [Layer 2] }\end{array}$ \\
\hline $\begin{array}{l}\text { Corresponding to } \\
\text { the level of }\end{array}$ & $\begin{array}{l}- \text { WCAG Principles } \\
\text {-WCAG } \\
\text { Guidelines } \\
\text {-CHD Principles } \\
\text {-CHD Guidelines }\end{array}$ & $\begin{array}{l}\text {-WCAG Success } \\
\text { criteria } \\
\text {-CHD Success } \\
\text { criteria } \\
\text {-e-Mag } \\
\text { Recommendations }\end{array}$ & $\begin{array}{l}- \text { e-Mag } \\
\text { Checkpoints } \\
\text { (Items) } \\
\text {-CHD WebAIM } \\
\text { Recommendations }\end{array}$ & \begin{tabular}{|l}
$\bullet M E D E-W E B$ \\
Assessment Items
\end{tabular} \\
\hline
\end{tabular}


The new created structure of layers reflects a hierarchy already presented by WCAG 2.0 in the approaching of information regarding the characteristic accessibility, but from the wider layer (Layer 0) to an even more specific one (Layer 3), representing the latter an innovation in the methodologies of accessibility assessment studied here.

The incorporation of assessment items pertaining to usability requirements presented by MEDE-WEB enables an additional detailing from the Layer 3 of the new hierarchical structure (Layer of requirements), in a new proposition for an assessment method of accessibility and usability in Web software, as shown in Figure 3:

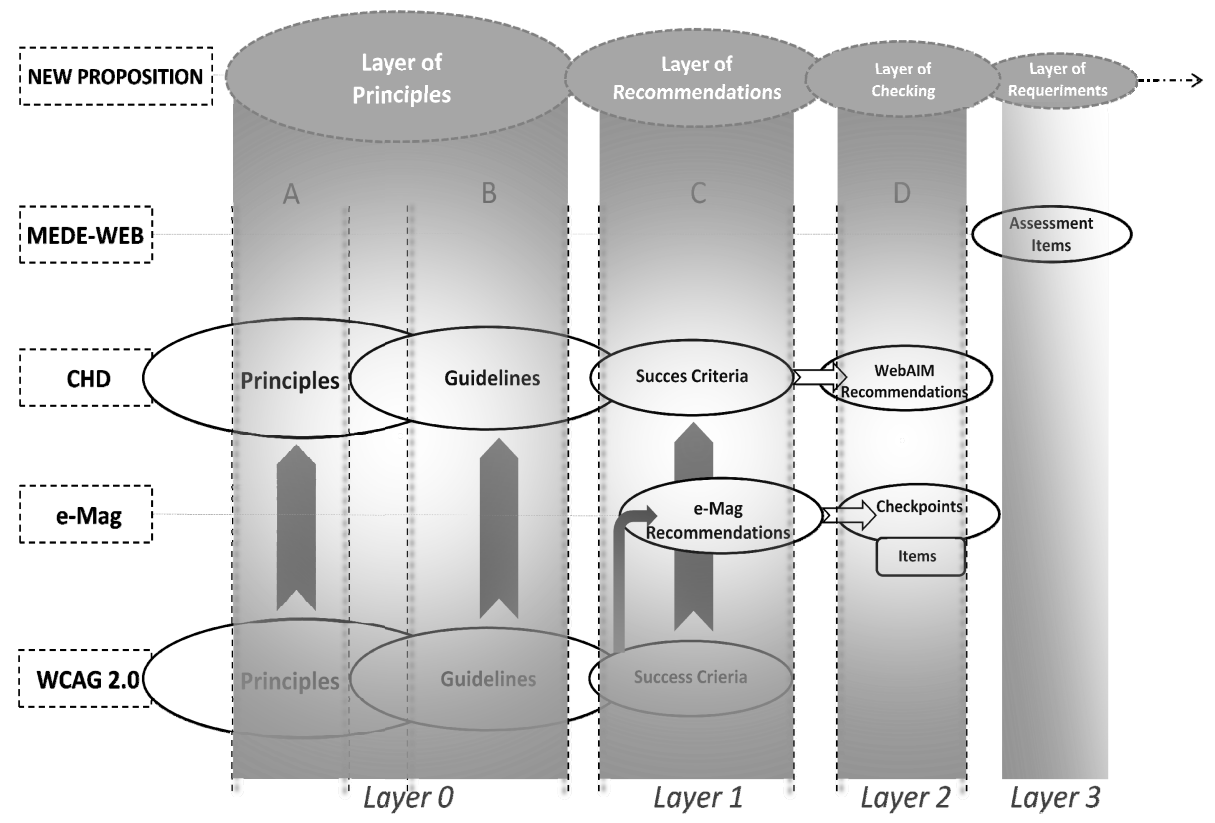

Fig. 3. New Hierarchical Structure of Layers of Guidance 
In Table 3, "titles" component of Web pages is applied into and interpreted within the new structure of layers of guidance of the proposed model:

Table 3. Application of the New Hierarchical Structure of Layers of Guidance

\begin{tabular}{|c|c|c|c|c|}
\hline \multicolumn{5}{|c|}{ Application of the New Hierarchical Structure of Layers of Guidance } \\
\hline $\begin{array}{l}\text { Layer of Guidance } \\
\text { Number and Name }\end{array}$ & $\begin{array}{c}\text { Layer } 0 \\
\text { Layer of } \\
\text { Principles }\end{array}$ & $\begin{array}{c}\text { Layer } 1 \\
\text { Layer of } \\
\text { Guidelines }\end{array}$ & $\begin{array}{l}\text { Layer } 2 \\
\text { Layer of } \\
\text { Checking }\end{array}$ & $\begin{array}{c}\text { Layer } 3 \\
\text { Layer of } \\
\text { Requirements }\end{array}$ \\
\hline $\begin{array}{c}\text { Titles } \\
\text { Component }\end{array}$ & $\begin{array}{l}\text { Principle 1: Perceivable } \\
\text { (WCAG) } \\
\text { Information and user } \\
\text { interface components must } \\
\text { be presentable to users in } \\
\text { ways they can perceive. } \\
\text { (CHD) } \\
\text { Web content is made } \\
\text { available to the senses - } \\
\text { sight, hearing, and/or touch } \\
\text { Guideline 1.3: Adaptable } \\
\text { Create content that can be } \\
\text { presented in different ways } \\
\text { (for example simpler } \\
\text { layout) without losing } \\
\text { information or structure. } \\
\text { Principle 2: Operable } \\
\text { (WCAG) } \\
\text { User interface components } \\
\text { and navigation must be } \\
\text { operable. } \\
\text { (CHD) } \\
\text { Interface forms, controls, } \\
\text { and navigation are operable } \\
\text { Guideline 2.4: Navigable } \\
\text { Provide ways to help users } \\
\text { navigate, find content, and } \\
\text { determine where they are. }\end{array}$ & $\begin{array}{l}\text { (WCAG and } C H D \text { ) } \\
\text { Success criteria 1.3.1: } \\
\text { Info and Relationships } \\
\text { Information, structure, } \\
\text { and relationships } \\
\text { conveyed through } \\
\text { presentation can be } \\
\text { programmatically } \\
\text { determined or are } \\
\text { available in text. } \\
\text { Success criteria 2.4.10: } \\
\text { Section Headings } \\
\text { (Titles) } \\
\text { Section headings are } \\
\text { used to organize the } \\
\text { content. } \\
\text { (e-Mag) } \\
\text { Recommendation 2: } \\
\text { Organize HTML code in } \\
\text { a logic and semantic } \\
\text { way } \\
\text { Recommendation 3: } \\
\text { Use heading layers } \\
\text { correctly }\end{array}$ & $\begin{array}{l}\text { (e-Mag) } \\
\text { Checking point (Item): } \\
\text { Titles present a logic order in } \\
\text { text? Are they described } \\
\text { correctly? } \\
(\text { CHD) } \\
\text { WebAIM's } \\
\text { Recommendation: } \\
\text { - (Success criteria 1.3.1) } \\
\text { Semantic markup is used to } \\
\text { designate headings... } \\
\text { Semantic markup is used } \\
\text { appropriately. } \\
\text { - (Success criteria 2.4.10) } \\
\text { Beyond providing an overall } \\
\text { document structure, } \\
\text { individual sections of content } \\
\text { are designated using } \\
\text { headings, where appropriate. }\end{array}$ & 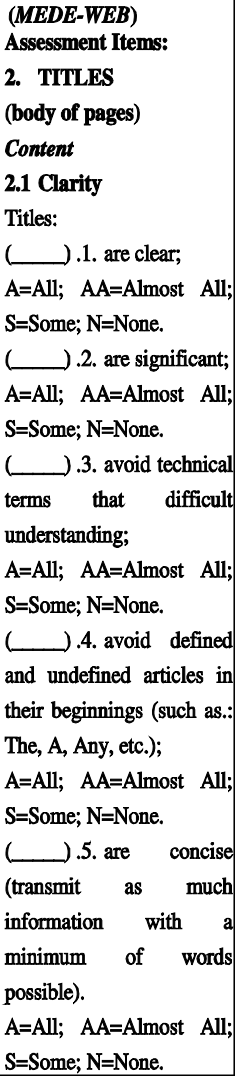 \\
\hline
\end{tabular}




\subsection{Accessibility and Usability Requirements in the New Structure - Layers 2 and 3}

The "titles" component can be analyzed within the new hierarchical structure by identifying the respective accessibility and usability requirements treated by the methods of Model e-Mag and MEDE-WEB, shown in a synthetic way in Table 4:

Table 4. Accessibility and Usability Requirements - Layers 2 and 3

\begin{tabular}{|c|c|c|}
\hline \multicolumn{3}{|c|}{$\begin{array}{l}\text { Accessibility and Usability Assessment Methods } \\
\text { AUTHORS X PROPERTIES }\end{array}$} \\
\hline \multirow{2}{*}{$\underbrace{\text { AUTHORS/Methods }}_{\text {PROPERTIES }}$} & $e-G O V$ & $C T I$ \\
\hline & $\begin{array}{l}\text { Model e-Mag } \\
\text { (Layer 2) }\end{array}$ & $\begin{array}{l}\text { MEDE-WEB } \\
\text { (Layer 3) }\end{array}$ \\
\hline \multicolumn{3}{|l|}{ TITLES } \\
\hline \multirow{12}{*}{$\begin{array}{c}\text { Accessibility and } \\
\text { Usability requirements }\end{array}$} & Logical order in text & \\
\hline & Correct description & \\
\hline & & Clear \\
\hline & & Significant \\
\hline & & Avoid technical terms \\
\hline & & Avoid articles \\
\hline & & Concise \\
\hline & & Consistent \\
\hline & & Different font sizes \\
\hline & & Easy-to-read colors \\
\hline & & Easy-to-read styles \\
\hline & & Avoid underlining \\
\hline
\end{tabular}

According to the proposals for a new assessment model, the treatment of such requirements is performed in two of the layers of guidance presented by the new hierarchical structure (Layer 2: Layer of checking and Layer 3: Layer of requirements) in a larger and more detailed set of assessment items, with the inclusion of the usability requirements of the latter (Layer 3 ). 
Finally in Table 5, a new set of accessibility and usability requirements identified for other Web page components is shown in Layers 2 and 3 of the new structure:

Table 5. Web Components X Accessibility and Usability Requirements

\begin{tabular}{|c|c|c|}
\hline \multicolumn{3}{|c|}{$\begin{array}{c}\text { Accessibility and Usability Assessment Methods } \\
\text { AUTHORS X PROPERTIES }\end{array}$} \\
\hline AUTHORS/Methods & $e-G O V$ & CTI \\
\hline PROPERTIES & $\begin{array}{c}\text { Model e-Mag } \\
\text { (Layer 2) }\end{array}$ & $\begin{array}{l}\text { MEDE-WEB } \\
\text { (Layer 3) }\end{array}$ \\
\hline \multicolumn{3}{|l|}{ LINKS } \\
\hline $\begin{array}{r}\text { Appropriate, meaningful and succinct } \\
\text { description }\end{array}$ & $\mathbf{X}$ & $\mathbf{X}$ \\
\hline $\begin{array}{r}\text { Explicit indication of the result of } \\
\text { access }\end{array}$ & & $\mathbf{X}$ \\
\hline Presentation of explanatory balloons & & $\mathbf{X}$ \\
\hline Balloons identify result to be accessed & & $\mathbf{X}$ \\
\hline Correct targeting & $\mathbf{X}$ & $\mathbf{X}$ \\
\hline Opening on page & $\mathbf{X}$ & \\
\hline Appropriate location & & $\mathbf{X}$ \\
\hline Appropriate external contents & & $\mathbf{X}$ \\
\hline Indication of exiting to external sites & & $\mathbf{X}$ \\
\hline $\begin{array}{r}\text { Default description for the same content } \\
\text { accessed }\end{array}$ & & $\mathbf{X}$ \\
\hline Use of underlining & & $\mathbf{X}$ \\
\hline Legible presentation & & $\mathbf{X}$ \\
\hline \multicolumn{3}{|l|}{ BUTTONS } \\
\hline Proper function & $\mathbf{X}$ & \\
\hline Presentation of description & $\mathbf{X}$ & \\
\hline Adequate description & $\mathbf{X}$ & \\
\hline $\begin{array}{r}\text { Representative on the content to be } \\
\text { accessed }\end{array}$ & & $\mathbf{X}$ \\
\hline $\begin{array}{r}\text { Keep the same purpose in different } \\
\text { pages }\end{array}$ & & $\mathbf{X}$ \\
\hline $\begin{array}{r}\text { Appropriate location for better } \\
\text { understanding }\end{array}$ & & $\mathbf{X}$ \\
\hline Expected content targeting & & $\mathbf{X}$ \\
\hline
\end{tabular}




\section{Conclusions}

The proposals for a new assessment method by the integration presented are justified in the existing complementarity between the methods studied and the new contributions emerged during the comparative process.

This represents from the point of view adopted in the study an innovation and proposition for the revision and extension of concepts applied to information considered to be accessible, without restrictions or prioritizations of any kind to the public profile of end users, even though observing and complying the specificities of its different components groups and the impossibility of answering all the needs by a unique standardized assessment approach.

The current study opens new opportunities for the exploration of the characteristic usability on the horizon of Web accessibility assessment.

\section{References}

1. W3C - World Wide Web Consortium; WAI - Web Accessibility Initiative: Web Content Accessibility Guidelines - WCAG 2.0 (2008), http: / /www . w3 . org / http: / / www . w3 . org/TR/WCAG2 0 / (acesso em June 2013)

2. Guerra, A.C., Colombo, R.M.T.: Tecnologia da Informação: Qualidade de Produto de Software, PBQP Software - Ministério da Ciência e Tecnologia, Secretaria de Política de Informática, Brasília (2009)

3. Centro de Tecnologia da Informação Renato Archer - CTI/MCT: LAPS - Laboratório de Tecnologia de Avaliação de Qualidade de Produto de Software; LAQS - Laboratório de Avaliação de Qualidade de Software: MEDE-PROS - Método de Avaliação da Qualidade de Produto de Software, versão 2006 e MEDE-WEB - Método de Avaliação da Qualidade de Websites, versã (2005)

4. Governo Eletrônico (e-GOV) - Ministério do Planejamento, Orçamento e Gestão, Secretaria de Logística e Tecnologia da Informação; Ministério da Educação, Secretaria de Educação Profissional e Tecnológica: e-Mag Versão 3.0 - Modelo de Acessibilidade em Governo Eletrônico (2011), http: / / www.governoeletronico.gov.br/, http: / / emag.governoeletronico.gov.br/emag/ (acesso em July 2013)

5. WebAIM - Web Accessibility In Mind: WebAIM's WCAG 2.0 Checklist for HTML Documents - CHD., http://webaim.org/standards/wcag/checklist/ (Acesso em ago. 2013) 